\title{
BIM - Barreiras institucionais para a sua implantação no Brasil
}

\author{
BIM - Institutional barriers to its implementation in Brazil
}

\author{
> Eduardo Sampaio Nardelli \\ Universidade Presbiteriana Mackenzie, Brasil \\ nardelli@mackenzie.br
}

\author{
> Lais Guerle Tonso \\ Universidade Presbiteriana Mackenzie, Brasil \\ laisgtonso@gmail.com
}

\begin{abstract}
This paper presents the current state of art of BIM implementation in Brazil and evaluates its maturity level using the framework of Succar (2013), following analyzes institutional barriers that hinder the advancement of this process in Brazilian construction chain and points out about future possibilities to increase it.
\end{abstract}

Keywords: BIM; Maturity of BIM; BIM in Brazil; Brazilian productivity in construction chain; Barriers to BIM in Brazil

\section{Introdução}

Desde meados da primeira década do ano 2000 o empenho para implantação no Brasil do processo BIM entrou numa espiral crescente envolvendo os vários setores da cadeia construtiva seguindo uma tendência internacional que já produzira, em alguns países, algumas aplicaçóes de referência e complexidade peculiar. (Eastman, 2008)

Alguns fatores locais contribuíram particularmente para a intensificação dessa iniciativa.

De um lado, é claro, o interesse da própria indústria dos desenvolvedores de aplicativos CAD em fazer a migração para os produtos da nova geração tecnológica.

De outro lado, o crescimento do mercado imobiliário brasileiro que, depois de cerca de dez anos de estabilidade econômica experimentou um processo inédito de expansão, não apenas em termos quantitativos, como também, em abrangência territorial pelo país.

A este cenário, deve-se acrescentar também o lançamento do Programa Minha Casa Minha Vida, com base no Fundo Nacional de Habitação de Interesse Social, inicialmente com a perspectiva de construção de 1 milhão de moradias, meta depois dobrada, no atual governo federal. (Nardelli, 2012)

Desse modo, rapidamente, várias companhias que atuam no setor passaram a ter centenas de empreendimentos concomitantes, a distâncias continentais entre si, sujeitos a diferentes legislaçóes urbanas locais, procedimentos para licenciamento de projetos e realidades de custos de material e mão de obra, compondo um cenário de grande complexidade gerencial.
Para mitigar essas dificuldades, as entidades representativas do setor empreenderam, então, várias açôes, algumas de caráter institucional, visando à simplificação e homogeneização da legislação urbana e dos procedimentos para o licenciamento das obras e outras de atualizaçáo e avanço tecnológico das práticas correntes da cadeia produtiva da construção civil no Brasil.

Neste contexto o BIM ganhou destaque e passou a ser visto como recurso essencial para garantir a assertividade dos resultados previstos nos empreendimentos, a partir dos estudos de viabilidade e projetos elaborados na fase de concepção e estruturação do investimento, quando são calculados os custos e a taxa interna de retorno, antes do lançamento do produto no mercado. (SECOVI, 2010)

Dessa forma, a partir de meados da primeira década dos anos 2000, uma verdadeira onda BIM desencadeou-se pelo país, com a realização de vários eventos de disseminação desse conhecimento, estruturaçáo de grupos de pesquisa nas universidades e grupos de trabalho nas entidades representativas do setor, articulados entre si e com as agências governamentais de fomento à pesquisa e instâncias de definição de políticas setoriais, como o MDIC - Ministério do Desenvolvimento, Indústria e Comércio e o MCT - Ministério da Ciência e Tecnologia, tendo como objetivo principal a implantação deste novo processo de produçáo de projetos no Brasil.

Além disso, algumas gigantes do setor se dispuseram elas próprias a realizar por sua conta e risco experiências de implantação do BIM, muitas vezes compartilhando cada passo com os demais agentes da cadeia construtiva. 
Acompanhando esta tendência as contrataçóes em âmbito governamental passaram a se interessar também em incorporar o novo processo de concepção e desenvolvimento de projetos, publicando editais de licitaçóes exigindo a utilizaçáo do BIM para o desenvolvimento dos produtos contratados.

Passados, no entanto, cerca de dez anos entre um momento e outro, os resultados que se colhem ainda são bastante modestos quando se considera o volume anual produzido de modo tradicional pela indústria da construção civil brasileira.

Que terá provocado este cenário?

Haveria alguma especificidade que pudéssemos apontar em relação ao Brasil?

Este é o tema que desenvolvemos a seguir.

\section{Antecedentes}

Em 2008 foi criado em São Paulo um Grupo de Trabalho interdisciplinar que reuniu as entidades representativas da cadeia produtiva da construção civil brasileira, incluindo algumas companhias incorporadoras do setor imobiliário, que deu início a um processo de disseminação sistemática do BIM - Building Information Modeling no Brasil, através de várias açóes coordenadas, como workshops e seminários.

Um ano depois, boa parte desse grupo compôs o colegiado que elaborou a NBR ISO 12006-2:2010, Organizaçáo da Informação da Construção, posteriormente complementada pelas NBR 159651:2011, Sistema de classificação da informação da construção Parte 1: Terminologia e Estrutura e NBR 15965-2:2012, Sistema de classificação da informaçẫo da construção Parte 2: Características dos Objetos da Construção, pendentes ainda mais três partes complementares.

Neste meio tempo, foram realizados diversos eventos sobre o BIM, organizados em âmbito acadêmico ou, autonomamente, pelas próprias entidades participantes do referido Grupo de Trabalho, nos quais além de contribuiçôes de palestrantes estrangeiros, alguns casos de sucesso brasileiros passaram a ser relatados, com destaque às dificuldades de integração entre as diversas disciplinas, o que realmente só veio a ocorrer em raríssimos relatos.

É de se destacar ainda a iniciativa do MCT - Ministério da Ciência e Tecnologia que em 2009 lançou a CHAMADA PÚBLICA MCT/MCIDADES/FINEP/Ação Transversal- SANEAMENTOAMBIENTAL E HABITAÇÃO - 7/2009, que resultou na criação de uma rede de pesquisa formada por sete universidades brasileiras com o objetivo de desenvolver soluçóes inovadoras em tecnologia da informação e comunicação aplicadas à construção, visando à melhoria da qualidade e produtividade do segmento da habitação de interesse social, com destaque para BIM - Building Information Modeling e outras soluçôes para suporte ao processo de gerenciamento de projetos; simulaçáo de desempenho e operaçáo de edificaçôes. Trabalho que segue em desenvolvimento.

Cabe registrar, também, o lançamento, em Março de 2014, do "Termo de Referência para desenvolvimento de projetos com o uso da Modelagem da Informaçáo da Construção (BIM)", elaborado pela Secretaria de Estado da Saúde de Santa Catarina.
Dos vários relatos, alguns casos referiram-se ao setor imobiliário, onde algumas empresas de destaque realizaram alguns projetos pilotos, tentando integrar as diversas disciplinas que compóem o projeto de um edifício sem, contudo, ir muito além da utilização de recursos como "clash detection" e quantificação de componentes.

Possibilidades como simulaçáo de desempenho, como parte do processo de concepção formal do edifício, ou mesmo a utilizaçâo de planilhas de áreas interagindo dinamicamente com a geometria, durante a realizaçáo dos estudos de viabilidade, sequer chegaram a ser mencionadas.

Em sua absoluta maioria, os casos relatados estiveram focados nos aspectos construtivos dos edifícios.

Também foram relatados casos de edifícios de empresas públicas, mas sempre com este viés, da questão construtiva.

Assim, estes foram os resultados obtidos após seis anos de grande empenho dos agentes da cadeia da construção civil brasileira no que se refere à implantação do BIM no Brasil.

Um processo em evoluçáo, certamente, mas aparentemente bastante modesto, tendo em vista a importância que este setor representa na economia brasileira.

\section{Grau de Maturidade}

Seria possível estabelecer uma medida relativa do grau de maturidade alcançado até aqui pelo setor em seu esforço de implantação do BIM no Brasil?

De acordo com Succar (2014), sim, é possível: a maturidade da implantação do BIM em Macro Escalas como um país, pode ser medida a partir de oito variáveis:

1. Objetivos, fases e marcos;

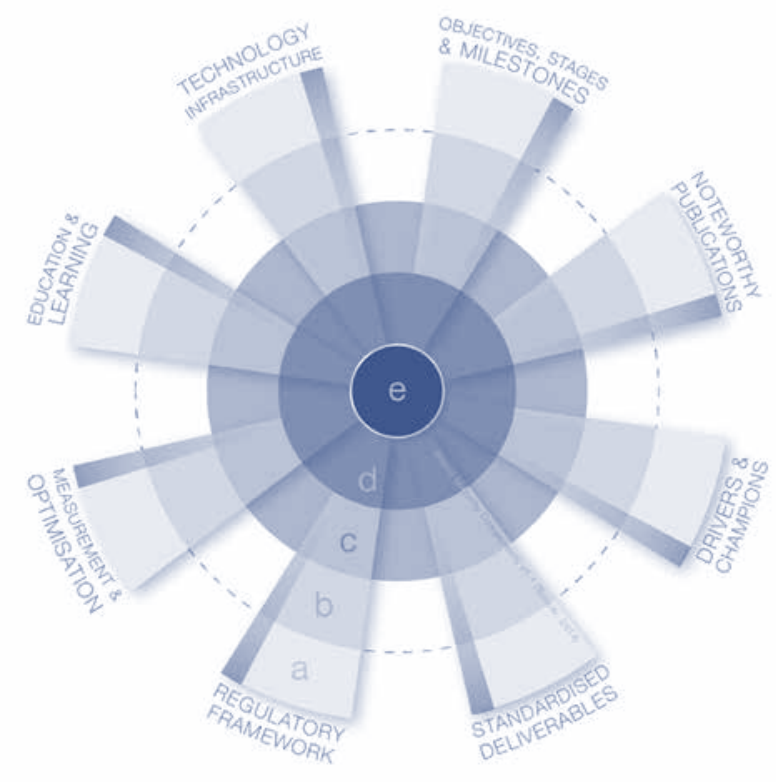

Figure 1: Diagrama de Macro Maturidade em BIM, criado por Succar (20.14), disponível em http://www.bimframework.info/, acesso em 20/09/2014 


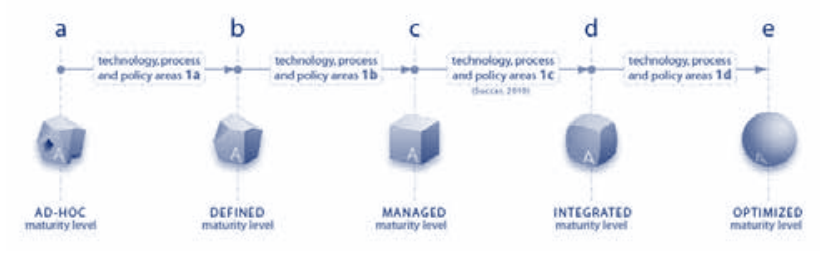

Figure 2: Diagrama BIM Maturity Index, criado por Succar (2013), disponível em http://www.bimframework.info/2013/12/bim-maturity-index.html, acesso em 20/09/2014.

2. Publicações de referência;

3. Diretrizes estabelecidas e casos de sucessos;

4. Normas técnicas;

5. Marco regulatório;

6. Indicadores de desempenho;

7. Sistemas de formação e capacitação;

8. Infraestrutura tecnológica.

Como se vê a seguir:

A partir desses indicadores, é possível estabelecer uma escala de graus de maturidade em cinco níveis, que vai do inicial ao otimizado, conforme ilustração:

Seguindo esta nomenclatura e comparando com a realidade brasileira atual verificamos que o país não vai muito além do nível inicial, tendo em vista as raras publicaçôes de referência nessa área, de fato, desenvolvidas no país (a maior parte são traduções de obras estrangeiras), marco regulatório incipiente (poucas Normas Técnicas, algumas ainda em andamento), muito poucos casos de sucesso, que realmente tenham integrado todas as disciplinas de um projeto e formação e capacitação inexistentes no currículo das escolas de arquitetura e engenharia brasileiras, na prática relegados aos cursos de treinamento para o uso de aplicativos BIM.

\section{Barreiras}

Como explicar este resultado táo modesto?

De imediato, evidencia-se que a implantação do BIM no Brasil jamais foi assumida como uma questão de Estado, com açốes coordenadas pelo governo federal, com metas de curto, médio e longo prazos estabelecidas em conjunto com a cadeia produtiva.

Iniciativas como as do MDIC-Ministério de Desenvolvimento Indústria e Comércio de coordenar em conjunto com a ABNT Associação Brasileira de Normas Técnicas a produção das NBR ISSO 12006-2: 2010, NBR 15965-1:2011 e NBR 15965-2:2012 e do MCT - Ministério de Ciência e Tecnologia de promover em parceria com a FINEP a pesquisa de usos avançados de tecnologia digital na produção de Habitaçóes de Interesse Social, através da CHAMADA PÚBLICA MCT/MCIDADES/FINEP/Ação Transversal- SANEAMENTOAMBIENTAL E HABITAÇÁO - 7/2009, foram, na verdade, atos isolados, que náo alcançaram o governo como um todo.

Assim, nunca foram equacionados os diversos gargalos que se constituem em poderosas barreiras para a conversão do segmento como, por exemplo, a questâo tributária que incide sobre os aplicativos e equipamentos, o estabelecimento de uma política de crédito subsidiado para a implantação dos sistemas capazes de operar o processo BIM, como acontece na atividade agrícola, por exemplo.

E, de forma ainda mais danosa, a legislação brasileira que normatiza as contrataçóes de projetos e obras públicas reflete uma preocupaçáo imediatista e sem qualquer compromisso com a qualidade do objeto contratado.

De fato, tanto a lei 8666/93 quanto o RDC - Regime Diferenciado de Contrataçáo - este criado para agilizar a contrataçáo de obras de infraestrutura para a Copa do Mundo e posteriormente ampliado para as obras do governo incluídas no PAC, Programa de Aceleração do Crescimento - têm como preocupação central apenas a contratação pelo menor preço, relativizando a importância da proposta técnica.

E, o que é ainda mais grave, em nenhum momento exigem a entrega do Projeto Completo, entendido aí como o conjunto de projetos executivos de todas as disciplinas que compóem o edifício.

Tendo em vista que o BIM propóe-se a antecipar através de modelos digitais os problemas construtivos de uma obra, com o objetivo de se garantir o melhor desempenho de uma edificação em todo o seu ciclo de vida, a sua efetiva implantação no país só pode se viabilizar se o maior contratante, que é o governo, tiver como preocupaçáo a contrataçáo de produtos que correspondam a essa expectativa.

Trata-se, portanto, de uma verdadeira revolução mental, uma mudança completa de paradigma: ao invés de focar a contratação de projetos e obras pelo menor preço, o Estado brasileiro deveria contratar projetos e obras que permitissem construir edifícios e espaços públicos com alto desempenho durante toda a sua vida útil.

Neste caso, entáo, o processo BIM emergiria como uma necessidade e, a partir daí, a sua implantação no país se tornaria, necessariamente, uma política de Estado.

E, por consequência, o país poderia se beneficiar, como um todo, de enormes ganhos de produtividade na cadeia produtiva da construçáo civil, contribuindo de forma geral, para o seu desenvolvimento.

Enquanto, porém, prevalecer o conceito imediatista na contratação de projetos e obras públicas no Brasil, a implantaçáo do processo BIM seguirá a passos lentos, com pequenos avanços conquistados a duras penas por agentes privados mais ousados, que encontrem escala e recursos para investir nesse processo de migração.

\section{Considerações Finais}

A possibilidade de ocorrer essa profunda transformaçáo no âmbito do Estado brasileiro é bastante remota de vez que a questão da contratação de projetos e obras públicas está diretamente ligada aos interesses políticos dos governantes, cuja ação está limitada ao alcance de seus próprios mandatos, de quatro anos.

Daí a pressa em contratar e entregar obras para garantir o seu prestígio junto aos eleitores e a sua consequente reeleição.

Desse modo, a hipótese de mudança está relacionada à compreensão que os eleitores, cidadãos brasileiros e, em última análise, os clientes finais, possam ter da importância de se construir edifícios 
e espaços públicos de qualidade, com desempenho garantido ao longo de toda a sua vida útil.

Compreensão que parece se esboçar de forma bastante tênue a partir dos protestos havidos em junho de 2013, quando a população, de modo bastante desordenado passou a reivindicar um padráo de qualidade para as áreas de educação, saúde e mobilidade urbana.

É preciso que a esta aspiração seja associada à ideia de desempenho para que, entáo, os clientes finais possam cobrar de nossos homens públicos a criação de um marco regulatório que viabilize novas formas de contratação com este viés.

Seria, na verdade, um passo decisivo de que carece o país como um todo, que parece ter chegado a um novo patamar, cuja superação depende basicamente da melhora da produtividade em todos os setores da economia.

Enquanto isso, algumas iniciativas podem gerar sinergias nessa direção.

Uma delas é a NBR 15575, conhecida como Norma de Desempenho, que impóe novos padróes de qualidade para os edifícios brasileiros e, por consequência, novas responsabilidades para os arquitetos, autores dos projetos.

Outra delas é a iniciativa do Exército Brasileiro de implantar o processo BIM para a gestáo de seus próprios - que somam uma área do tamanho do Estado de Sergipe - em todo o seu respectivo ciclo de vida, articulando-se para isso, com os agentes privados da cadeia produtiva da construção civil além das instituiçôes governamentais.

A proposta prevê um prazo de dois anos para sua implantação, com metas de curto, médio e longo prazos, que atendem a todas as oito variáveis propostas por Succar (2014) em sua matriz de avaliação da maturidade de implantação do BIM em sistemas de Macro Escala.

São agentes com este poder de indução que, efetivamente, podem dar um novo impulso à implantaçáo do BIM no Brasil.

Não por acaso, uma situação semelhante ao que ocorreu nos EUA, onde o Exército americano teve um papel relevante como indutor dessa difícil, mas, necessária transição.

\section{Referências}

ASSOCIAÇÃO BRASILEIRA DE NORMAS TÉCNICAS NBR

ISO 12006: Construção de edificação — Organização de informaçáo da construção. Rio de Janeiro, 2010.

Eastman, Chuck et alli - BIM HANDBOOK-A guide to Building Information Modeling for Owners, Managers, Designers, Engineers and Contractors - John Wiley and Sons, Inc., 2008

Mohamad, Kassem, Bilal Succar \& Nashwan Dawood (2013) A Proposed Approach to Comparing the BIM Maturity of Countries, Proceedings of the CIB W78 2013: 30th International Conference-Beijing, China, 9-12 October

Nardelli, Eduardo Sampaio (2012) Desafios do Programa Minha Casa Minha Vida frente ao processo BIM - Building Information Modeling: migrando para o IPD - Integrated Project Delivery [BIM process challenges of My Home My Life Program: migrating to IPD - integrated project delivery], SIGraDi 2012 [Proceedings of the 16th Iberoamerican Congress of Digital Graphics] Brasil - Fortaleza 13-16 November 2012, pp. 505-508 http://cumincad.scix.net/cgi-bin/works/ Show?sigradi2012_250 - acesso em 20/04/2014

SECOVI, 2010 - http://www.secovi.com.br/noticias/a-importancia-da-inovacao-tecnologica-para-fortalecimento-do-mercado -imobiliario/4035/ - acesso em 20/04/2014

SECOVI, 2012 - http://www.secovi.com.br/noticias/quem-nao-estiver-em-rede-e-peixe-fora-dagua/5413/- acesso em 20/04/2014

Succar, Bilal, Willy Sher \& Anthony Williams (2012) Measuring BIMperformance: Five metrics, Architectural Engineering and Design Management, 8:2, 120-142

Valor Econômico, 2001 - Incorporadores buscam saídas para financiar novos projetos - http://www.valor.com.br/arquivo/1000017378/incorporadores-buscam-saidas-para-financiarnovos-projetos - acesso em 20/04/2014

http://www.bimframework.info/2013/12/bim-maturity-index.

html - acesso em 20/09/2014

http://www.bimframework.info - 